\title{
Qualidade física e sensorial de biscoitos doces com fécula de mandioca
}

\author{
Physical and sensorial quality of sweet cookies with cassava starch
}

\author{
Jucyanne Carvalho Vieira ${ }^{\mathrm{I}}$ Flávio Martins Montenegro ${ }^{\mathrm{II}}$ Alessandra Santos Lopes ${ }^{\mathrm{II}}$ \\ Rosinelson da Silva Pena ${ }^{\text {III* }}$
}

\section{RESUMO}

Neste trabalho, foi avaliada a substituição de 5 , 10 e $15 \%$ de farinha de trigo por fécula de mandioca na elaboração de biscoito doce. Ambas, farinha e fécula, foram submetidas à caracterização físico-química, reológica e análise térmica diferencial (DTA). Os biscoitos produzidos foram comparados por meio de análises sensoriais e microbiológicas. $O$ resultado da análise térmica diferencial não mostrou qualquer alteração no comportamento de gelatinização do amido. O teste de aceitação sensorial mostrou que a crocância foi o único atributo que apresentou diferença significativa, indicando a viabilidade técnica de substituição da farinha de trigo por $15 \%$ de fécula de mandioca.

Palavras-chave: biscoito, reologia, aceitação sensorial, análise térmica diferencial.

\section{ABSTRACT}

This research evaluated the substitution of 5,10 and $15 \%$ of wheat flour for cassava starch in sweet cookies production. Both, flour and starch were submitted to the physicochemical, rheological and differential thermal analysis (DTA). The produced cookies were compared through sensory and microbiological analyses. The DTA result didn't show any alteration in the starch gelatinization behavior. The result of the sensory acceptance analysis showed that crispness is the unique attribute that presented significant difference, indicating the technical viability of wheat flour substitution for $15 \%$ of cassava starch.

Key words: cookie, rheology, sensory acceptance, differential thermal analysis.

\section{INTRODUÇÃO}

A mandioca (Manihot esculenta Crantz) é uma planta da família da Euphorbiaceae, originária do Brasil, da região da bacia tropical do Amazonas, difundida para outros países da América do Sul e Central (CEREDA, 2005). Conhecida também como aipim, macaxeira, yuca, tapioca e cassava, é cultivada em todo território brasileiro, assumindo destacada importância na alimentação humana e animal, além de ser utilizada como matéria-prima industrial, amplamente e diversificadamente. Além da tradicional farinha de mandioca, existem mais de 200 produtos derivados da mandioca, entre eles a fécula (IPARDES, 2004).

A fécula desponta como um produto da mandioca, capaz de agregar valor a ela e gerar emprego e renda, além de apresentar grandes perspectivas de ser usada na panificação. Uma iniciativa nesse sentido foi um Projeto de Lei (PL), aprovado pelo Senado Federal em 2008, obrigando que, nas aquisições por órgãos públicos, através de verbas federais, a farinha de trigo e seus derivados recebessem mistura de fécula de mandioca (CUNHA, 2008). O presidente Lula vetou este PL.

Também conhecida como polvilho doce ou goma, a fécula de mandioca é um pó fino, branco, inodoro, insípido, que produz ligeira crepitação quando

'Universidade Federal do Pará (UFPA), Belém, PA, Brasil.

${ }^{\text {II } C e r e a l ~ C h o c o t e c ~(I T A L), ~ C a m p i n a s, ~ S P, ~ B r a s i l . ~}$

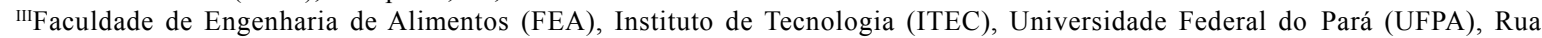
Augusto Corrêa, 1, Guamá, 66075-900, Belém, PA, Brasil. E-mail: rspena@ufpa.br. Autor para correspondência. 
comprimido entre os dedos. É obtida das raízes da mandioca, após descascamento, trituração, desintegração, purificação, peneiramento, centrifugação, concentração e secagem (CAMARGO et al., 1984).

O Pará é o maior produtor brasileiro de mandioca, com 4,8 milhões de toneladas em 2008 (IBGE, 2008), enquanto o Paraná é o maior produtor de fécula, com $62 \%$ da produção brasileira, no mesmo ano; seguido pelo Mato Grosso do Sul com 19\% e São Paulo com 14\% (CEPEA, 2008).

A fécula de mandioca é constituída, em média, por $18 \%$ de amilose e $82 \%$ de amilopectina (CEREDA et al., 2001). A faixa de temperatura de gelatinização do amido de milho é $75-80^{\circ} \mathrm{C}$, enquanto para a fécula de batata é de $60-65^{\circ} \mathrm{C}$ e para a fécula de mandioca é de $65-70^{\circ} \mathrm{C}$ (ARIAS, 2000). Essa propriedade permite que, em processos no qual o amido seja substituído pela fécula, os processos térmicos ocorram em temperaturas mais baixas.

O biscoito, também chamado de bolacha, é o produto obtido pelo amassamento e cozimento conveniente de massas preparadas com farinhas, amidos e féculas; fermentadas ou não. Outras substâncias alimentícias, tais como a gordura hidrogenada proveniente da soja, também são utilizadas como matérias-primas (MARANGONI, 2007).

O objetivo deste trabalho foi avaliar a qualidade física e sensorial do biscoito doce, elaborado com farinha mista, em que parte da farinha de trigo foi substituída por fécula de mandioca, bem como caracterizar as farinhas e a fécula de mandioca utilizadas na elaboração do produto.

\section{MATERIAL E MÉTODOS}

Matérias-primas

Os ingredientes: farinha de trigo, fécula de mandioca, amido de milho, sal, bicarbonato de amônia, gordura vegetal hidrogenada, açúcar (sacarose), açúcar invertido, lecitina de soja e aroma de baunilha foram adquiridos em estabelecimentos comerciais da cidade de Belém (PA).

Processo de produção dos biscoitos

No processo de produção dos biscoitos tipo moldado doce, realizaram-se as seguintes etapas: pesagem dos ingredientes, mistura, laminação, modelagem, corte, assamento, resfriamento, embalagem e armazenamento. Inicialmente, foram preparadas farinhas mistas com substituições de 5, 10 e $15 \%$ da farinha de trigo por fécula de mandioca. As formulações são apresentadas na tabela 1 .

\section{Análises}

Análises físico-químicas - Foram realizadas na farinha de trigo, fécula de mandioca e/ou no produto, as seguintes análises: umidade (método 44-15A, da AACC, 2000); acidez titulável; proteínas, pelo método de Kjeldahl; lipídios, por extração com éter de petróleo (métodos 940.22, 920.87 e 922.06, da AOAC, 1997, respectivamente); cinzas das farinhas mistas, da fécula e do biscoito, por incineração a $920^{\circ} \mathrm{C}\left(\right.$ norma ${ }^{\circ} 104$, da ICC, Brasil, 1996), $550^{\circ} \mathrm{C}$ (método 930.05, da AOAC, 1997) e $550^{\circ} \mathrm{C}$ (método 08-01, da AACC, 2000), respectivamente, e glúten, em sistema Glutomatic (método 38-12A, da AACC, 2000). As análises físico-

Tabela 1 - Formulações utilizadas na elaboração do biscoito doce com proporções variadas de fécula de mandioca.

\begin{tabular}{|c|c|c|c|c|}
\hline \multirow{2}{*}{ Ingredientes } & \multicolumn{4}{|c|}{-------\% de substituição de farinha de trigo por fécula de mandioca no biscoito doce.------- } \\
\hline & 0 & 5 & 10 & 15 \\
\hline Farinha de trigo $(\mathrm{g})$ & 6,65 & 6,32 & 5,99 & 5,65 \\
\hline Fécula de mandioca $(\mathrm{g})$ & 0,00 & 0,33 & 0,67 & 1,00 \\
\hline Amido de milho (g) & 11,50 & 11,50 & 11,50 & 11,50 \\
\hline $\mathrm{Sal}(\mathrm{g})$ & 0,55 & 0,55 & 0,55 & 0,55 \\
\hline Bicarbonato de amônia (g) & 0,29 & 0,29 & 0,29 & 0,29 \\
\hline Gordura vegetal hidrogenada (g) & 31,00 & 31,00 & 31,00 & 31,00 \\
\hline Açúcar refinado $(\mathrm{g})$ & 24,25 & 24,25 & 24,25 & 24,25 \\
\hline Açúcar invertido (g) & 24,25 & 24,25 & 24,25 & 24,25 \\
\hline Lecitina de soja $(\mathrm{g})$ & 0,40 & 0,40 & 0,40 & 0,40 \\
\hline Aroma de baunilha (g) & 1,11 & 1,11 & 1,11 & 1,11 \\
\hline Água (mL) & q.o. & q.o. & q.o. & q.o. \\
\hline
\end{tabular}

q.o. - Quantidade ótima. 
químicas dos biscoitos foram realizadas apenas para a formulação padrão e para a formulação que apresentou os melhores resultados.

Análises reológicas - Farinografia - foram avaliadas a capacidade das farinhas em absorver água e a estabilidade delas, em farinógrafo Brabender; Alveografia - para determinação da força de glúten das farinhas (W) e da razão tenacidade/extensibilidade $(\mathrm{P} /$ L), foi utilizado alveógrafo Chopin e atividade da enzima $\alpha$-amilase - determinada em equipamento Falling number da Perten - fundamenta-se na rápida gelatinização do amido em suspensão aquosa, quando submetido a aquecimento em banho-maria $\left(\approx 100^{\circ} \mathrm{C}\right)$ e na subsequente liquefação do gel formado pela ação da $\alpha$-amilase presente na amostra (conforme métodos daAACC, 2000, 54-21, 54-30Ae 56-81, respectivamente).

Análise térmica - Para avaliar as transformações que ocorreram durante o processo de cozimento das diferentes farinhas, foi realizada análise térmica diferencial (DTA), em equipamento PL - STA da Thermal Sciences, com aquecimento de $20^{\circ} \mathrm{C} \mathrm{min}^{-1} \mathrm{e}$ passagem de ar com velocidade de $50 \mathrm{~mL} \mathrm{~min}^{-1}$, baseado em CHARSLEY \& WARRINGTON (1992).

Avaliação microbiológica - Foi realizada de acordo com VANDERZANT \& SPLITTSTOESSER (1992). Foram determinados coliformes a $45^{\circ} \mathrm{C}$ e Salmonella sp., segundo padrões microbiológicos recomendados pela legislação brasileira (BRASIL, 2001).

Determinação de cor - Foi realizada nos biscoitos com farinha de trigo e com $15 \%$ de substituição, em colorímetro digital da marca KONICA MINOLTA, modelo CR-400. O resultado expressa a variação de cor $\left(\Delta \mathrm{E}^{*}\right)$ através da Equação 1.

$\Delta \mathrm{E}^{*}=\left(\mathrm{a}^{* 2}+\mathrm{b}^{* 2}+\mathrm{L}^{* 2}\right)^{1 / 2}$

Determinação da atividade de água - Foi realizada nos biscoitos com farinha de trigo e com $15 \%$ de substituição, usando higrômetro AQUAlab 3TE da Decagon, a $26^{\circ} \mathrm{C}$.

Avaliação física dos biscoitos - Foram determinados o peso inicial da massa, o peso do biscoito assado e o diâmetro dos biscoitos (este último com paquímetro).

Análise sensorial - Os biscoitos foram submetidos à análise sensorial, através de testes de aceitação e de intenção de compra (STONE \& SIDEL, 1993), realizados com 30 provadores não treinados de ambos os sexos. Os testes de aceitação foram realizados, com escala hedônica de nove pontos, sendo avaliados os atributos: cor, aparência, sabor e crocância. As amostras foram codificadas com três dígitos. Para o cálculo do índice de aceitação (IA) e do índice de intenção de compra (IC), foi utilizada a Equação 2, em que M é a média das notas obtidas e X a nota máxima, a qual foi 9 para o teste de aceitabilidade e 5 para o teste de intenção de compra.

IA ou IC $=\frac{M}{X} \times 100 \%$

Análise estatística

Os resultados dos parâmetros físicoquímicos e sensoriais foram submetidos à análise de variância (ANOVA), com teste complementar de Tukey, para efeitos de comparação.

\section{RESULTADOS E DISCUSSÃO}

Caracterização físico-química e reológica das farinhas Na tabela 2, são apresentados os valores médios, com os respectivos desvios padrão, das análises físico-químicas e de parâmetros de qualidade das farinhas utilizadas. A umidade, o teor de cinzas e a acidez da farinha de trigo atenderam à legislação brasileira, que estipula teores máximos de $15 \%, 0,8 \%$, e

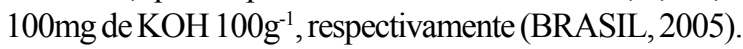
O teor de proteína também atendeu a mesma legislação, que estipula valor mínimo de 7,5\%. Em relação ao teor de lipídios, constatou-se que a adição da fécula não alterou esse parâmetro significativamente, para nenhuma das farinhas mistas.

Os teores de glúten úmido das farinhas estão de acordo com os encontrados por COSTA et al. (2008), que variaram de 22,60 a 29,17\%, já os teores de proteína foram inferiores aos encontrados por GUTKOSKI et al. (2008), que variaram de 11,42 a $12,67 \%$. Os teores de glúten demonstraram que as farinhas possuem glúten de boa qualidade, o que foi comprovado pelos elevados valores do índice de glúten. Quando este é inferior a 40, indica glúten de baixa qualidade; entre 40-60, glúten originado de farinhas médias; e, superior a 60 , está relacionado com glúten de boa qualidade (MONTENEGRO \& ORMENESE, 2008).

Com base no farinograma, pode-se afirmar que a farinha mista com $15 \%$ de fécula de mandioca foi a mais indicada para ser utilizada na formulação de biscoitos; quando comparada com as farinhas mistas com 5 e $10 \%$ de fécula. COSTA et al. (2008) encontraram valores de capacidade de absorção de água e estabilidade da massa na faixa de 53,3 a $57,6 \%$ e 10,0 e 24,75 minutos, respectivamente, para farinhas obtidas de grãos de trigo nacional.

De acordo com a análise alveográfica, a energia de deformação da massa ou força da farinha 
Tabela 2 - Análises físico-químicas e qualidade tecnológica das farinhas utilizadas no preparo de biscoitos doces com proporções variadas de fécula de mandioca.

\begin{tabular}{|c|c|c|c|c|c|}
\hline Determinações & Farinha de trigo & Fécula de mandioca & Farinha mista $5 \%$ & Farinha mista $10 \%$ & Farinha mista $15 \%$ \\
\hline Umidade (\% b.u.)* & $13,53 \pm 0,02^{b}$ & $13,99 \pm 0,04^{\mathrm{a}}$ & $14,04 \pm 0,04^{\mathrm{a}}$ & $13,40 \pm 0,24^{b}$ & $13,83 \pm 0,23^{\mathrm{a}, \mathrm{b}}$ \\
\hline $\begin{array}{l}\text { Acidez (mL sol. } \mathrm{N} \mathrm{de} \mathrm{NaOH} \\
\left.100 \mathrm{~g}^{-1}\right)^{*}\end{array}$ & $0,442 \pm 0,006^{\mathrm{a}}$ & $0,149 \pm 0,01^{\mathrm{e}}$ & $0,395 \pm 0,005^{\mathrm{b}}$ & $0,372 \pm 0,006^{\mathrm{c}}$ & $0,339 \pm 0,0^{\mathrm{d}}$ \\
\hline Cinzas $(\% \text { b.s. })^{*}$ & $0,58 \pm 0,10^{\mathrm{a}}$ & $0,11 \pm 0,03^{\mathrm{b}}$ & $0,60 \pm 0,10^{\mathrm{a}}$ & $0,52 \pm 0,10^{\mathrm{a}}$ & $0,41 \pm 0,10^{\mathrm{a}}$ \\
\hline Proteínas (\% b.s.)* & $10,13 \pm 1,00^{\mathrm{a}}$ & $0,17 \pm 0,00^{\mathrm{b}}$ & $10,11 \pm 0,01^{\mathrm{a}}$ & $\frac{\Delta}{9,54 \pm 0,10^{\mathrm{a}}}$ & $9,06 \pm 0,01^{\mathrm{a}}$ \\
\hline Lipídios (\% b.s.)* & $1,17 \pm 0,35^{\mathrm{a}}$ & $0,24 \pm 0,06^{\mathrm{b}}$ & $1,29 \pm 0,12^{\mathrm{a}}$ & $1,22 \pm 0,03^{\mathrm{a}}$ & $1,17 \pm 0,06^{\mathrm{a}}$ \\
\hline Glúten úmido** & $24,70 \pm 0,22^{\mathrm{a}, \mathrm{b}}$ & - & $25,53 \pm 0,43^{\mathrm{a}}$ & $23,50 \pm 1,30^{\mathrm{b}}$ & $24,38 \pm 0,21^{\mathrm{a}, \mathrm{b}}$ \\
\hline Glúten seco** & $8,53 \pm 0,10^{\mathrm{a}}$ & - & $8,73 \pm 0,17^{\mathrm{a}}$ & $8,80 \pm 0,66^{\mathrm{a}}$ & $8,50 \pm 0,11^{\mathrm{a}}$ \\
\hline Índice de glúten** & $98 \pm 1^{\mathrm{a}}$ & - & $98 \pm 0^{\mathrm{a}}$ & $98 \pm 1^{\mathrm{a}}$ & $98 \pm 1^{\mathrm{a}}$ \\
\hline Absorção de água (\%) & 56,5 & - & 56,0 & 56,6 & 58,2 \\
\hline Estabilidade (min) & 12,5 & - & 13,5 & 12,0 & 3,0 \\
\hline Força de glúten, $\mathrm{W}$ (x $\left.10^{-4} \mathrm{~J}\right)$ & 220 & - & 220 & 220 & 250 \\
\hline $\begin{array}{l}\text { Relação tenacidade/ } \\
\text { extensibilidade, } \mathrm{P} / \mathrm{L}\end{array}$ & 1,22 & - & 2,43 & 1,34 & 1,79 \\
\hline Número de queda $(\mathrm{s})^{* *}$ & $393 \pm 21^{\mathrm{b}}$ & - & $393 \pm 5^{\mathrm{b}}$ & $358 \pm 15^{\mathrm{c}}$ & $456 \pm 19^{\mathrm{a}}$ \\
\hline
\end{tabular}

* Média de três determinações; ** Média de quatro determinações; b.u. - base úmida; b.s. - base seca. Letras diferentes na mesma linha indicam diferença significativa (Teste de Tukey a $5 \%$ de significância).

(W), $230 \times 10^{-4} \mathrm{~J}$ a $250 \times 10^{-4} \mathrm{~J}$, e a relação tenacidade/ extensibilidade $(\mathrm{P} / \mathrm{L})(1,34$ a 2,43$)$ evidenciaram que as três farinhas mistas apresentaram características mais elásticas (maior tenacidade que extensibilidade), indicando não serem as mais adequadas para produção de biscoitos; para os quais são indicadas farinhas mais extensíveis (DOBRASZCZYK \& MORGENSTERNB, 2003).

Valores de número de queda, entre 300 e 400 s, estatisticamente superior para a farinha com $15 \%$ de fécula, indicaram que a ação da $\alpha$ amilase foi baixa nas amostras analisadas. Segundo GUTKOSKI et al. (2008), valores nessa ordem de grandeza indicam que a farinha de trigo utilizada foi originada de trigo não germinado e com boas condições de armazenamento. A $\alpha$-amilase atua principalmente sobre o amido danificado e no amido gelatinizado, provocando a quebra das cadeias e diminuindo a viscosidade da suspensão.

Análise térmica das farinhas

Com base na análise térmica diferencial (DTA), tanto a fécula de mandioca, quanto as farinhas mistas apresentaram um único evento abaixo de $300^{\circ} \mathrm{C}$, o qual é endotérmico e ocorreu entre 60 e $80^{\circ} \mathrm{C}$, característico da gelatinização do amido, o que já foi observado por MYLLÄRINEN et al. (1998). Constatase, dessa forma, que a gelatinização do amido foi a única modificação estrutural que ocorreu na faixa de temperatura utilizada no assamento do biscoito
$\left(\mathrm{T}<200^{\circ} \mathrm{C}\right)$. Esse resultado comprovou o fato de que a adição da fécula sobre a farinha de trigo não provoca modificações no comportamento térmico do amido.

Caracterização e avaliação microbiológica dos biscoitos Os resultados das análises físicas e físicoquímicas realizadas nos biscoitos doces são apresentados na tabela 3. O peso dos biscoitos assados diferiu estatisticamente, ao nível de $5 \%$, enquanto os diâmetros mantiveram-se iguais, indicando que as diferentes perdas de massa não provocaram contrações distintas. FASOLIN et al. (2007) observaram uma relação de proporcionalidade entre tais parâmetros, para um produto similar.

Comparando a composição do biscoito com $15 \%$ de fécula, com a do biscoito padrão, pode-se observar que os teores de cinzas e de lipídios mantiveram-se constantes, enquanto o teor de proteínas reduziu. FASOLIN et al. (2007) e ASSIS et al. (2009), ao elaborarem biscoitos doces, substituindo parte da farinha de trigo por farinha de banana e farinhas de aveia ou de arroz, respectivamente, observaram teores de cinzas e proteínas superiores e de lipídios inferiores aos do biscoito elaborado com $15 \%$ de fécula do presente estudo. A umidade foi idêntica à observada por FASOLIN et al. (2007) em biscoitos com farinha de banana e, conforme SCOTT (1957), os níveis de atividade de água $\left(\mathrm{a}_{\mathrm{w}}\right.$ ) observados $\left(a_{w}<0,6\right)$ asseguram a estabilidade microbiológica dos biscoitos. 
Tabela 3 - Características físicas e físico-químicas dos biscoitos doces preparados com diferentes proporções de fécula de mandioca.

\begin{tabular}{|c|c|c|c|c|}
\hline \multirow{2}{*}{ Determinações } & \multicolumn{4}{|c|}{----\% de substituição de farinha de trigo por fécula de mandioca no biscoito doce. --- } \\
\hline & 0 & 5 & 10 & 15 \\
\hline Peso inicial da massa $(\mathrm{g})$ & 228,15 & 225,02 & 223,21 & 224,35 \\
\hline Peso do biscoito assado (g)* & $62,70 \pm 0,32^{\mathrm{a}}$ & $56,13 \pm 0,43^{\mathrm{c}}$ & $58,56 \pm 0,84^{\mathrm{b}}$ & $53,37 \pm 0,51^{\mathrm{d}}$ \\
\hline Diâmetro $(\mathrm{mm})^{*}$ & $46,86 \pm 1,01^{\mathrm{a}}$ & $46,56 \pm 0,86^{\mathrm{a}}$ & $46,93 \pm 0,96^{\mathrm{a}}$ & $45,23 \pm 0,49^{\mathrm{a}}$ \\
\hline Umidade (\% b.u.)* & $2,60 \pm 0,02^{\mathrm{b}}$ & ND & ND & $2,80 \pm 0,01^{\mathrm{a}}$ \\
\hline Cinzas $(\% \text { b.s. })^{*}$ & $0,56 \pm 0,03^{\mathrm{a}}$ & ND & ND & $0,49 \pm 0,06^{\mathrm{a}}$ \\
\hline Proteínas (\% b.s.)* & $4,69 \pm 0,05^{\mathrm{a}}$ & ND & ND & $3,17 \pm 0,53^{b}$ \\
\hline Lipídios (\% b.s.)* & $27,98 \pm 1,00^{\mathrm{a}}$ & ND & ND & $28,67 \pm 0,71^{\mathrm{a}}$ \\
\hline Atividade de água $\left(26^{\circ} \mathrm{C}\right)^{*}$ & $0,39 \pm 0,01^{\mathrm{a}}$ & ND & ND & $0,31 \pm 0,01^{\mathrm{b}}$ \\
\hline $\operatorname{Cor}\left(\Delta \mathrm{E}^{*}\right)^{*}$ & ND & ND & ND & $1,99 \pm 0,29$ \\
\hline
\end{tabular}

* Média de três determinações; b.u. - base úmida; b.s. - base seca; ND - Não determinado; $\Delta \mathrm{E}^{*}$ - Diferença de cor em relação ao biscoito padrão. Letras diferentes na mesma linha indicam diferença significativa (Teste de Tukey a $5 \%$ de significância).

O valor de $\Delta \mathrm{E}^{*}=1,99$ para o biscoito com $15 \%$ de fécula indicou que a adição de fécula de mandioca interferiu na coloração final do produto, tornando-o mais claro. Variações da mesma ordem de grandeza foram observadas por ASSIS et al. (2009), para biscoitos doces, quando até $100 \%$ da farinha de trigo foi substituída por farinha de aveia. Valores superiores foram observados quando a substituição foi feita por farinha de arroz, o que foi atribuído ao fato de essa farinha ser mais escura.

Nas análises microbiológicas das amostras de biscoito doce, com $0,5,10$ e $15 \%$ de fécula de mandioca, constatou-se a ausência de coliformes a $45^{\circ} \mathrm{C}$ e de Salmonella $s p$. Dessa forma, o produto atendeu à legislação brasileira (BRASIL, 2001), que exige valores de coliformes a $45^{\circ} \mathrm{C}$ inferiores a $10 \mathrm{NPM}$ $\mathrm{g}^{-1}$ e ausência de Salmonella $s p$. em $25 \mathrm{~g}$.

Análise sensorial e intenção de compra

Os índices de aceitação (IA), para os atributos avaliados, são apresentados na tabela 4. A ANOVA demonstrou que o atributo crocância foi o

Tabela 4 - Índice de aceitação para as diferentes formulações de biscoito doce preparados com diferentes proporções de fécula de mandioca.

\begin{tabular}{lrcr}
\hline Formulações & IC (Cor) & IC (Crocância) & IC (Sabor) \\
\hline Branco & $71,48^{\mathrm{a}}$ & $70,00^{\mathrm{b}}$ & $76,67^{\mathrm{a}}$ \\
A (5\%) & $78,15^{\mathrm{a}}$ & $69,26^{\mathrm{b}}$ & $80,74^{\mathrm{a}}$ \\
B (10\%) & $76,67^{\mathrm{a}}$ & $79,26^{\mathrm{b}}$ & $81,48^{\mathrm{a}}$ \\
C (15\%) & $74,81^{\mathrm{a}}$ & $82,96^{\mathrm{a}}$ & $83,70^{\mathrm{a}}$ \\
\hline
\end{tabular}

Letras diferentes na mesma coluna indicam diferença significativa (Teste de Tukey a 5\% de significância). único que apresentou diferença significativa $(\mathrm{P}<0,01)$, sendo o biscoito doce obtido com farinha mista com $15 \%$ de fécula de mandioca o preferido pelos provadores. Esse resultado ratifica o resultado da análise reológica para esta farinha mista, o qual a apontou como sendo aquela que apresentou os melhores atributos para a elaboração de biscoitos. Os IA de todos os biscoitos doces formulados foram superiores aos observados por FASOLIN et al. (2007), para produtos similares.

O resultado do teste de intenção de compra indicou que os biscoitos elaborados com as farinhas mistas com 10 e $15 \%$ de fécula foram os que obtiveram as melhores notas na intenção de compra, as quais podem ser consideradas como muito boas. Fazendo a somatória da nota dos itens "certamente compraria" e "provavelmente compraria", os produtos obtiveram as notas: $71 \%$ e $67 \%$, respectivamente. Para as formulações sem fécula e com $5 \%$ de fécula, essas notas foram $29 \%$ e $42 \%$, respectivamente. Com base nesta avaliação, pode-se afirmar que as formulações 10 e $15 \%$ teriam boas aceitações se colocadas no mercado.

\section{CONCLUSÃO}

A avaliação geral dos resultados de características físico-químicas e reológicas, dos testes de aceitabilidade e de intenção de compra, mostraram ser tecnicamente viável a elaboração de biscoito doce, com substituição de até $15 \%$ da farinha de trigo por fécula de mandioca.

A formulação com $15 \%$ de fécula de mandioca foi a mais indicada por ter obtido melhores índices de aceitação para o parâmetro crocância. A substituição de parte do trigo, produto na sua maioria importado, pela fécula de mandioca, capaz de ser 
produzida na maioria das regiões brasileiras, é apresentada como uma alternativa para a redução do custo do produto, ou, pelo menos, para a utilização de farinhas totalmente nacionais; trazendo dividendos para o Brasil.

\section{REFERÊNCIAS}

AACC. American Association of Cereal Chemists. Approved methods of the AACC. 9.ed. St. Paul: AACC, 1995. 1200p.

AOAC. Association of Official Analytical Chemists. Official methods of analysis of the AOAC International. 16.ed. 3.rev. Washington, 1997. 1141p.

ARIAS, L.V.B. Fécula de mandioca e polvilho azedo para fabricação de pão de queijo. In: PIZZINATTO, A; ORMENESE, R.C.S.S. Seminário pão de queijo: ingredientes, formulação e processo. Campinas: Governo do estado de São Paulo/ Secretaria de Agricultura e Abastecimento/Agência Paulista de Tecnologia dos Agronegócios/Instituto de Tecnologia de Alimentos/Centro de Tecnologia de Cereais e Chocolate, 2000. p.1-14.

ASSIS, L.M. et al. Propriedades nutricionais, tecnológicas e sensoriais de biscoitos com substituição de farinha de trigo por farinha de aveia ou farinha de arroz parboilizado. Alimentos e Nutrição, Araraquara, v.20, n.1, p.15-24, 2009. Disponível em: <http://200.145.71.150/seer/index.php/alimentos/article/ view/944/771>. Acesso em: 27 abr. 2010.

BRASIL. Agência Nacional de Vigilância Sanitária. Portaria n.354, de 18 de julho de 1996 . Norma Técnica referente a Farinha de Trigo. Diário Oficial [da República Federativa do Brasil], Brasília, 22 jul. 1996. Secção 1, p.57.

BRASIL. Agência Nacional de Vigilância Sanitária. Resolução RDC n.12, de 02 de janeiro de 2001. Regulamento Técnico sobre padrões microbiológicos para alimentos. Diário Oficial [da República Federativa do Brasil], Brasília, 10 jan. 2001. Secção 1, p.45.

BRASIL. Ministério da Agricultura, Pecuária e Abastecimento. Instrução Normativa n.8, de 2 de junho de 2005. Regulamento Técnico de Identidade e Qualidade da Farinha de Trigo. Diário Oficial [da República Federativa do Brasil], Brasília, 03 jun. 2005. Secção 1, p.91.

CAMARGO, R. et al. Tecnologia de produtos agropecuários - Alimentos. São Paulo: Nobel, 1984. 289p.

CEPEA. Centro de Estudos Avançados em Economia Aplicada. Produção de fécula cresce $3,7 \%$ em 2008 , mas se concentra em algumas regiões. Acesso em: 10 dez. 2009. Online. Disponível em: http://www.cepea.esalq.usp.br/pdf/ Producao_fecula_2008.pdf.

CEREDA, M.P. Processamento de raízes de mandioca para uso culinário. In.: EMBRAPA MANDIOCA E FRUTICULTURA TROPICAL. Processamento e utilização da mandioca. Brasília: Embrapa Informação Tecnológica, 2005. 547p.

CEREDA, M.P. et al. Biotecnologia industrial. In: Modificação de fécula por fermentação. São Paulo: Edgard Blücher, 2001. p.413-460

COSTA, M.G. et al. Qualidade tecnológica de grãos e farinhas de trigo nacionais e importados. Ciência e Tecnologia de Alimentos, Campinas, v.28, n.1, p.220-225, 2008. Disponível em: <http://www.scielo.br/pdf/cta/v28n1/30.pdf >. Acesso em: 22 abr. 2010. doi: 10.1590/S0101-20612008000100031.
CUNHA, L. Uso da fécula de mandioca no pão é aprovado no Senado. São Paulo: Infobibos, 2008. Acesso em: 18 abr. 2010. Online. Disponível em: <http://www.infobibos.com/ Artigos/2008_3/fecula/index.htm>.

CHARSLEY, E.L.; WARRINGTON, S.B. Thermal analysis: techniques and applications. Cambridge: Royal Society of Chemistry, 1992. 296p.

DOBRASZCZYK, B.J.; MORGENSTERNB, M.P. Rheology and the breadmaking process. Journal of Cereal Science, London, v.38, n.3, p.229-245, 2003. Disponível em: <http://

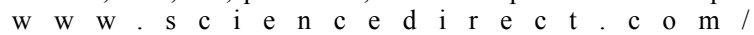
science?_ob=MImg\&_imagekey=B6WHK-49HDR52-4$19 \&$ \& c di $=6853 \&$ \& user $=686466 \&$ \& pi $=$ S 07335 $21003000596 \&$ origin $=$ browse \& zon e $=$ r $\mathrm{s} 1 \mathrm{t}$ list item \& coverDate=11\%2 F $30 \% 2 \mathrm{~F}$ $2003 \&$ s k $=999619996 \& \mathrm{wchp}=\mathrm{dG} \mathrm{LbVtz}-$ zSkzV\&md5=4e7c2567cdf0ff14996f6a 1cd5b7ad78\&ie $=$ / sdarticle.pdf>. Acesso em: 26 abr. 2010. doi: 10.1016/S07335210(03)00059-6.

FASOLIN, L.H. et al. Biscoitos produzidos com farinha de banana: avaliações química, física e sensorial. Ciência e Tecnologia de Alimentos, Campinas, v.27, n.3, p.524-529, 2007. Disponível em: <http://www.scielo.br/pdf/cta/v27n3/ a16v27n3.pdf>. Acesso em: 24 abr. 2010. doi: 10.1590/S010120612007000300016

GUTKOSKI, L.C. et al. Efeito do período de maturação de grãos nas propriedades físicas e reológicas de trigo. Ciência e Tecnologia de Alimentos, Campinas, v.28, n.4, p.888-894, 2008. Disponível em: <http://www.scielo.br/pdf/cta/v28n4/ a19v28n4.pdf>. Acesso em: 26 abr. 2010. doi: 10.1590/S010120612008000400019

IBGE. Instituto Brasileiro de Geografia e Estatística. Produção agrícola municipal 2008. Rio de Janeiro. Acesso em: 10 dez. 2009. Online. Disponível em: http://www.ibge.gov.br.

IPARDES. Instituto Paranaense de Desenvolvimento Econômico e Social. Arranjo produtivo da mandioca da região de Paranavaí-Loanda no Estado do Paraná. Curitiba, 2004. 95p.

MARANGONI, A.L. Potencialidade de aplicação de farinha de Yacon (Polymnia sonchifolia) em produtos à base de cereais. 2007. 104f. Dissertação (Mestrado em Ciência e Tecnologia de Alimentos) - Universidade Estadual de Campinas, SP.

MONTENEGRO, F.M.; ORMENESE, R.C.S.C. Avaliação da qualidade tecnológica da farinha de trigo. Campinas: Cereal Chocotec ITAL, 2008. 62p.

MYLLÄRINEN, P. et al. Heat-induced structural changes of small and large barley starch granules. Journal of the Institute of Brewing, London, v.104, n.6, p.343-349, 1998. Disponível em: <http://www.scientificsocieties.org/jib/papers/1998/ 1998_104_6_343.pdf>. Acesso em: 27 abr. 2010.

SCOTT, W.J. Water relations of food spoilage microorganisms. Advances in Food Research, New York, v.7, n.1, p.83-127, 1957.

STONE, H.S.; SIDEL, J.L. Sensory evaluation practices. 2.ed. San Diego: Academic, 1993. 338p.

VANDERZANT, C.; SPlitTSTOESSER, D. Compendium of methods for the microbiological examination of food. 3.ed. Washington: American Public Heath, 1992. 1108p. 